\title{
Transition metal oxide thin films for nonvolatile resistive random access memory applications
}

\author{
Dinghua BAO ${ }^{\dagger}$ \\ State Key Laboratory of Optoelectronic Materials and Technologies, School of Physics and Engineering, Sun Yat-Sen University, \\ Guangzhou 510275, P.R. China
}

Resistive random access memory (RRAM) based on reversible bistable resistance switching effect is attracting much attention for its superior properties such as nonvolatility, long retention time, simple device structure, small size, and low operating voltage. The unique resistance switching properties have been observed in some binary transition metal oxides, perovskite oxides, and organic molecular materials. This paper briefly reviews the status and new progress on binary transition metal oxide thin film materials such as $\mathrm{NiO}, \mathrm{TiO}_{2}, \mathrm{ZrO}_{2}, \mathrm{ZnO}$, and their multilayered thin films and metal nanocomposite thin films, for resistive random access memory applications, and also presents some of our own research work in this field. There is no doubt that study on transition metal oxide thin films for RRAM application will have been a topic of great interest in the forthcoming years, and it is expected that better understanding of physical mechanisms for the bistable resistance switching of the transition metal oxide thin films sandwiched between two metal electrodes can be achieved.

(C2009 The Ceramic Society of Japan. All rights reserved.

Key-words : Transition metal oxide thin film, Multilayered thin film, Metal nanocomposite thin film, Resistance switching, Resistive random access memory

\section{Introduction}

Transition metal oxide thin films exhibit important bistable resistance switching properties which can be used for resistive random access memory (RRAM) applications. ${ }^{1)-3)}$ In recent years, due to the increasing request for better properties of transition metal oxide thin films for RRAM device applications and importance of fundamental research, this kind of transition metal oxide thin films have received much attention. Various transition metal oxide thin films have been fabricated to obtain better resistance switching properties, and to explore physical mechanism of resistance switching. ${ }^{4-6)}$ On the other hand, the recent studies have already demonstrated the enhancement of the resistance switching properties due to doping or constructing multilayered structure or metal nanocomposite thin films with respect to the individual transition metal oxide thin films.

Several important growth methods have been used to prepare this kind of transition metal oxide thin films, including sputtering, pulsed laser deposition (PLD), metalorganic chemical vapor deposition, chemical solution deposition, and atomic layer deposition. Each method has its own advantages and disadvantages for preparing transition metal oxide thin films. For preparation of the transition metal oxide thin films, selection of electrode materials is important because electrode material and the interface between electrode and film have an influence on resistance switching properties. On the other hand, role of defects must be taken into consideration.

Up to now, there have been more and more studies on transition metal oxide thin films for RRAM applications, and several review papers on perovskite oxide thin films and transition metal oxide thin films have been published that can provide us some understanding of the research field. ${ }^{7)-10)}$ In this paper, we briefly

Corresponding author: D. Bao; E-mail: stsbdh@mail.sysu.edu.cn review the status and new progress on several typical transition metal oxide thin films such as $\mathrm{NiO}, \mathrm{TiO}_{2}, \mathrm{ZrO}_{2}, \mathrm{ZnO}$, and their multilayered thin films or metal nanocomposite thin films, for RRAM applications with some of our own research work in this field.

\section{Several important binary transition metal oxide thin films}

\section{1 $\mathrm{NiO}$ thin films}

$\mathrm{NiO}$ is one of the most promising transition metal oxide materials for RRAM applications. Due to its simple composition and structure, studies of $\mathrm{NiO}$ thin films have been interesting. Studies of $\mathrm{NiO}$ mainly focused on enhancing resistance ratio of high resistance state to low resistance state and improving resistance switching properties. For RRAM applications based on $\mathrm{NiO}$ thin films, understanding of the physical mechanism of conductive filament formation and rapture and obtaining direct experimental evidence for resistance switching of $\mathrm{NiO}$ thin films are major subjects. Park and coworkers observed electric-field induced $\mathrm{Ni}$ filament channels in polycrystalline $\mathrm{NiO}_{x}$ films and found that the irreversible low resistance state facilitates further increase of $\mathrm{Ni}$ filament channels and $\mathrm{Ni}$ filament density. ${ }^{11)}$ To visualize nano-sized conducting filamentary paths in the surface of $\mathrm{NiO}$ thin films during repetitive resistance switching, a current sensing-atomic force microscopy was used to observe random and localized resistive switching in $\mathrm{Pt} / \mathrm{NiO} / \mathrm{Pt}^{12)}$ Some areas (or spots), which were assumed to be the beginning of the conducting filaments, appeared (formation) and disappeared (rupture) in a localized and random fashion during the switching and are thought to contribute to resistive memory switching. The formation and rupture of conducting filaments of $\mathrm{NiO}$ thin films with $\mathrm{Hg} / \mathrm{NiO} / \mathrm{Pt}$ structure were also directly observed for a high resistive state and a low resistive state by a conducting atomic force microscope (CAFM) ${ }^{13)}$ Figure 1 shows the CAFM images of 


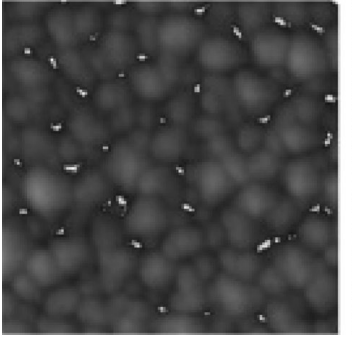

(a) $500 \mathrm{~nm}$

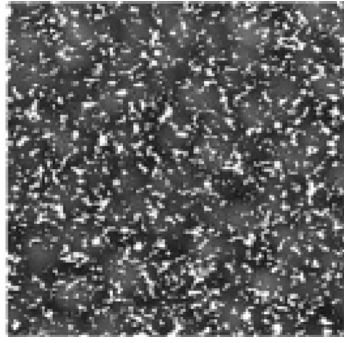

(b)

$500 \mathrm{~nm}$
Fig. 1. CAFM images of the NiO thin film (a) for the $R_{\text {off }}$ state and (b) for the $R_{\mathrm{on}}$ state corresponding to 100 switching cycles. ${ }^{13)}$

the NiO thin film (a) for the $R_{\text {off }}$ state and (b) for the $R_{\text {on }}$ state corresponding to 100 switching cycles. Considering that the conductive filament controls the localized current flow in the low resistive state of NiO-based RRAM devices, it is significant to evaluate the conductive filament temperature during operation. Recently, a statistical characterization of the critical filament temperature for the transition of switching from low resistance state to the high resistance state by the thermal dissolution of the conductive filament was performed by Russo et al.. ${ }^{14)}$ In addition, temperature dependence of high- and low-resistance states in $\mathrm{NiO}$ films is a concern for NiO-based RRAM. Studies of the temperature dependence of the resistance switching of $\mathrm{NiO}$ thin films in the temperature range of $10 \mathrm{~K}<\mathrm{T}<300 \mathrm{~K}$ indicated that metallic Ni defects might play a key role in the formation of a metallic channel. ${ }^{15)}$ These studies are helpful to further understanding of resistance switching mechanism of $\mathrm{NiO}$ thin films.

Structural defects such as Ni vacancies or oxygen vacancies or grain boundaries might have important influence on resistance switching properties of $\mathrm{NiO}$ films. This has been confirmed by Park et al. ${ }^{16)}$ and Park et al.. ${ }^{17)}$ The former prepared NiO thin films on $\mathrm{Pt} / \mathrm{Ti} / \mathrm{SiO}_{2} / \mathrm{Si}$ substrates by rf reactive sputtering, and found that the resistive switching behavior has a strong dependence on oxygen content, might relating to $\mathrm{Ni}$ vacancies and compensating holes inside the $\mathrm{NiO}$ film. The latter investigated the resistive switching characteristics of two types of $\mathrm{Pt} / \mathrm{NiO} / \mathrm{Pt}$ structures with epitaxial and polycrystalline $\mathrm{NiO}$ layers. Results indicated that $\mathrm{Pt} /$ polycrystalline-NiO/Pt showed very reproducible switching behavior, much better than Pt/epitaxial-NiO/Pt. This meant that microstructural defects may play a crucial role in the reliability of the resistive switching behavior.

Electrode is another important factor possibly affecting resistance switching properties of $\mathrm{NiO}$ thin films. Lee and coworkers studied the effects of various metal electrodes including $\mathrm{Ni}$, $\mathrm{Ni}_{0.83} \mathrm{Pt}_{0.17}$ alloy, $\mathrm{Ta}, \mathrm{Al}, \mathrm{Ag}$, and $\mathrm{Cu}$ electrodes on the resistance switching of polycrystalline $\mathrm{NiO}$ thin films. ${ }^{18)-19)}$ Their results showed that different from the belief that due to its high work function, $\mathrm{Pt}$ enables Ohmic contact to p-type $\mathrm{NiO}$, resistive switching was observed in $\mathrm{NiO}$ thin films using $\mathrm{Ta}$ or $\mathrm{Al}$ electrodes with a low work function. The resistive switching of films using an $\mathrm{Ag}$ or $\mathrm{Cu}$ top electrode with a low work function and high free energy of oxidation shows the importance of the formation of an oxide layer at the metal/NiO interface.

Interfacial reactions between electrode and transition oxide thin film were found to affect resistive switching behaviors of metal/NiO/metal structures. Characterization of the interfacial reactions between $\mathrm{NiO}$ and the electrode can provide insights on the switching mechanism. Studies ${ }^{20)}$ indicated that when a positive bias was applied to the $\mathrm{Pt}$ electrode, $\mathrm{Ag} / \mathrm{NiO} / \mathrm{Pt}$ structures exhibited reproducible resistive switching. However, if a positive

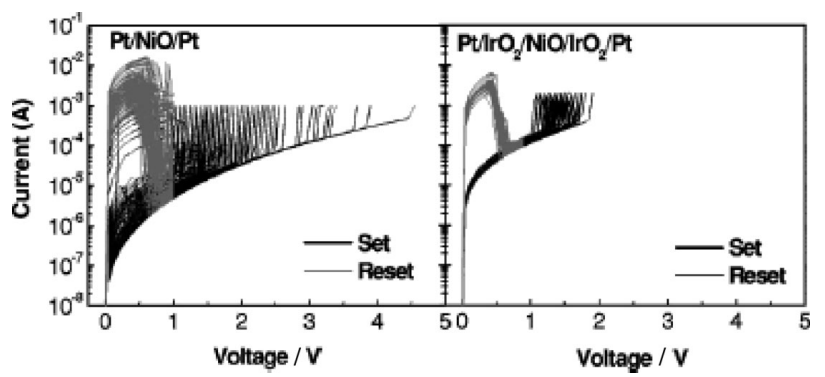

Fig. 2. $I-V$ curves of memory switching in $\mathrm{Pt} / \mathrm{NiO} / \mathrm{Pt}$ and $\mathrm{Pr} / \mathrm{IrO}_{2} / \mathrm{NiO} /$ $\mathrm{IrO}_{2} / \mathrm{Pt}$ memory cells. The data are from continuous memory switchings of 200 times. $^{22)}$

bias was applied to the $\mathrm{Ag}$ electrode, the $\mathrm{Ag} / \mathrm{NiO} / \mathrm{Pt}$ structures did not exhibit resistive switching behavior. Further analysis by $\mathrm{X}$-ray photoemission spectra revealed that different interfacial chemical interactions for the two cases may affect filament formation and rupture processes near the electrode and hence alter the resistive switching behaviors.

Effect of doping on resistance switching properties of $\mathrm{NiO}$ thin films is worth studying. Jung et al. studied the effects of Lidoping on bistable resistance switching in polycrystalline $\mathrm{NiO}$ film in the temperature range of $10 \mathrm{~K}<\mathrm{T}<300 \mathrm{~K}^{21)}$ It was believed that Li-doping could improve retention properties of $\mathrm{NiO}$ thin films and stability of switching between low resistance state and high resistance state.

Improvement of resistance switching in $\mathrm{NiO}$ such as minimizing the dispersions of all memory switching parameters can be achieved using thin $\mathrm{IrO}_{2}$ layers between $\mathrm{NiO}$ and electrodes. ${ }^{22}$ Figure 2 shows $I-V$ curves of memory switching in $\mathrm{Pt} / \mathrm{NiO} / \mathrm{Pt}$ and $\mathrm{Pr} / \mathrm{IrO}_{2} / \mathrm{NiO} / \mathrm{IrO}_{2} / \mathrm{Pt}$ memory cells. The data are from continuous memory switchings of 200 times. Note that in $\mathrm{NiO}$ thin films with noble metal electrodes, broad dispersions of switching parameters are generally observed during continuous switching cycles. The $\mathrm{IrO}_{2}$ thin layer was thought to help stabilize the local oxygen migrations for the filament formation and rupture, therefore leading to more stable memory switching parameters.

Recently, Sato et al. reported on fabrication of a resistive random access memory consisting of $\mathrm{NiO}$ resistive memories and control transistors with $0.18 \mu \mathrm{m}$ CMOS technology. ${ }^{23)}$ The initial forming voltage is as low as $2 \mathrm{~V}$ for $\mathrm{NiO}$ thin film, and the reset current is lower than $100 \mu \mathrm{A}$ due to control of filamentary conductance by current limit of MOSFET, by using the current limit of a selected cell transistor in the set process (1T-1R). The current level was determined by its gate voltage, resulting in the control of electrical resistance of the filamentary conductive paths in the low resistive state. In addition, a large voltage increase in the reset operation, which may cause an undesirable set operation, was also suppressed by a voltage-clamp transistor connected to the $1 \mathrm{~T}-1 \mathrm{R}$ cell in series. On the basis of these proposed switching schemes, the stable pulse operation was demonstrated successfully, indicating good potential of this device design.

\section{$2.2 \mathrm{TiO}_{2}, \mathrm{ZrO}_{2}$, and $\mathrm{HfO}_{2}$ thin films}

Usually, $\mathrm{TiO}_{2}$ thin films exhibit anatase or rutile phase structures depending on difference of deposition temperatures or preparation methods. Studies have confirmed that both phase structures showed bipolar resistive switching behavior. ${ }^{24)-25)}$ In addition, influence of crystalline constituent on resistive switching properties of $\mathrm{Pt} / \mathrm{TiO}_{2} / \mathrm{Pt}$ was also studied. ${ }^{26)}$ It was observed that the leakage current in the high-resistance state depended on 
the crystal phase composition of $\mathrm{TiO}_{2}$ thin films; however, the current of the thin films in the low-resistance state was hardly affected. High-resolution scanning transmission electron microscopy characterization of $\mathrm{TiO}_{2}$ anatase nanolayer of about $2.5 \mathrm{~nm}$ thick on TiN thin film suggested that the resistive change was due to the Mott transition in the $\mathrm{TiO}_{2}$ anatase nanolayer which could relate to the formation of filament paths. $\left.{ }^{25}\right)$

From different switching behaviors of $\mathrm{Pt} / \mathrm{TiO}_{2} / \mathrm{Pt}$ and $\mathrm{Ir}(\mathrm{O}) / \mathrm{TiO}_{2} /$ $\mathrm{Pt}$, the mechanism of resistance switching of $\mathrm{TiO}_{2}$ thin films was suggested to be local rupture and recovery of conducting filaments near the anode interface. ${ }^{27)}$ Further study indicated that only small part of the conducting filaments in the thin films near the anode contributed to the resistance switching. While another study on the influence of electron injection on the resistive switching of $\mathrm{Pt} / \mathrm{TiO}_{2} /$ Pt structure indicated that when the carrier injection by Schottky emission or space-charge-limited conduction was excessive, the resistance switching from the high resistance state to the low resistance state by a filamentary mechanism was suppressed. ${ }^{28)}$

Resistive switching properties of polycrystalline $\mathrm{TiO}_{2}$ thin film sandwiched between the Pt electrodes could be enhanced using a tungsten nitride barrier layer. ${ }^{29)}$ This enhancement can be attributed to the decrease in the number of oxygen vacancies at the interfaces between the $\mathrm{Pt}$ electrode and the $\mathrm{TiO}_{2}$ layer due to the inserted tungsten nitride buffer layer. $\mathrm{Gd}$ doping of $\mathrm{TiO}_{2}$ films was also found to improve resistive switching characteristics of $\mathrm{TiO}_{2}$-based resistive memory devices such as decreasing dispersions of resistive switching parameters due to continuous resistive switching. ${ }^{30)}$

If the transition metal oxide thin films deposited directly on $\mathrm{Si}$ substrates exhibit resistive switching properties, this would be of significance because of compatibility with conventional semiconductor process. Won et al. fabricated sputter-Pt/atomic layer deposition $\mathrm{TiO}_{2} / \mathrm{n}^{+}-\mathrm{Si}$ structures for resistive random access memory. ${ }^{31)}$ As a result, after annealing $\mathrm{Pt}(100 \mathrm{~nm}) / \mathrm{TiO}_{2}(38 \mathrm{~nm}) / \mathrm{n}^{+}-\mathrm{Si}$ structures in an $\mathrm{O}_{2}$ ambient at a temperature range of 100 to $500^{\circ} \mathrm{C}$, the resistive switching behavior was observed.

Lee et al. also prepared $\mathrm{ZrO}_{x}$ thin films on $\mathrm{p}^{+}-\mathrm{Si}$ substrates with a $\mathrm{Pt} / \mathrm{ZrO}_{x} / \mathrm{p}^{+}-\mathrm{Si}$ sandwich structure by reactive sputtering, and observed two stable resistance states. ${ }^{32)}$ The resistance switching of this $\mathrm{Pt} / \mathrm{ZrO}_{x} / \mathrm{p}^{+}-\mathrm{Si}$ sandwich structure was explained by electron trapping and detrapping of excess $\mathrm{Zr}^{+}$ions in transition layer which could affect the distribution of electric field inside the oxide, and, hence the current flow.

Effect of top electrode materials on resistive switching characteristics of $\mathrm{ZrO}_{2}$ films has been studied. ${ }^{33)}$ Compared with Pt/ $\mathrm{ZrO}_{2} / \mathrm{Pt}$ and $\mathrm{Al} / \mathrm{ZrO} \mathrm{O}_{2} / \mathrm{Pt}$ devices, $\mathrm{Ti} / \mathrm{ZrO}_{2} / \mathrm{Pt}$ device exhibits better resistive switching properties. For example, the resistive switching parameters of the $\mathrm{Pt} / \mathrm{ZrO}_{2} / \mathrm{Pt}$ and $\mathrm{Al} / \mathrm{ZrO}_{2} / \mathrm{Pt}$ devices exhibited a broad dispersion during continuous resistive switching cycles, but those dispersions are suppressed by using $\mathrm{Ti}$ as a top electrode for $\mathrm{Ti} / \mathrm{ZrO}_{2} / \mathrm{Pt}$ device.

It is well known that $\mathrm{HfO}_{2}$ is a promising high-k dielectric material. Recently, $\mathrm{HfO}_{2}$ has been reported to exhibit resistive switching behavior. The polycrystalline $\mathrm{HfO}_{2}$ films with graded compositions of $\mathrm{Hf}$ and $\mathrm{O}$ atoms grown by metallorganic chemical vapor deposition at $400^{\circ} \mathrm{C}$ had high resistance ratios of about $10^{4}-10^{9}$, and low operation voltage below $2 \mathrm{~V}^{34)}$ The resistance ratio was higher than those of other comparable materials, such as $\mathrm{TiO}_{2}$ and $\mathrm{ZrO}_{2}$. Nonstoichiometric hafnium oxide thin films with $\mathrm{Pt} / \mathrm{HfO}_{x} / \mathrm{TiN} / \mathrm{Si}$ structure were also reported to show stable resistance switching behavior with low-power operation. ${ }^{35}$ )

In addition, $\mathrm{Pt} / \mathrm{CeO}_{2} / \mathrm{Pt}$ structure also had a repeatable resistive switching behavior with a resistance ratio between two memory states of about five orders of magnitude. ${ }^{36)}$

\section{3 $\mathrm{ZnO}$ thin films}

Villafuerte et al. firstly reported on nonvolatile resistance switching of $\mathrm{S}$ and Co doped $\mathrm{ZnO}$ thin films deposited on different substrates using magnetron sputtering and pulsed laser deposition. ${ }^{37)}$ In the Co doped $\mathrm{ZnO}$ samples, the two resistance states were remarkably stable and uniform. Later, highly (002)oriented $\mathrm{ZnO}$ thin films with $\mathrm{Pt} / \mathrm{ZnO} / \mathrm{Pt}$ configuration were prepared by radio frequency magnetron sputtering at room temperature. ${ }^{38)}$ The $\mathrm{Pt} / \mathrm{ZnO} / \mathrm{Pt}$ devices also exhibited reversible and steady bistable resistance switching behaviors with a narrow dispersion of the resistance states and switching voltage. The resistance ratios of high resistance state to low resistance state were in the range of 3-4 orders of magnitude within 100 cycles of test. The conduction mechanisms dominating the low and high resistance states were thought to be Ohmic behavior and PooleFrenkel emission, respectively.

TiN/ZnO/Pt sandwich structures were also observed highly stable bipolar resistive switching behavior with fast switching speed ( $<20 \mathrm{~ns}$ for set and $<60 \mathrm{~ns}$ for reset), long retention (in the order of $10^{5} \mathrm{~s}$ ), and no need of electroforming process. ${ }^{39), 40)}$ The bipolar switching behaviors were explained by formation and rupture of the filamentary conductive path consisting of oxygen vacancies. The generation/recovery of oxygen vacancies and nonlattice oxygen ions were suggested to play a critical role in resistance switching.

Considering that $\mathrm{Mg}$-doped $\mathrm{ZnO}$ is a very important multifunctional material, Bao research group firstly studied the resistance switching properties of the $\mathrm{Mg}$-doped $\mathrm{ZnO}$ thin films. ${ }^{41), 42)}$ They prepared highly $c$-axis oriented $\mathrm{Mg}_{0.2} \mathrm{Zn}_{0.8} \mathrm{O}$ thin films with hexagonal structure on $\mathrm{Pt} / \mathrm{TiO}_{2} / \mathrm{SiO}_{2} / \mathrm{Si}$ substrates by sol-gel spin coating technique. The $\mathrm{Pt} / \mathrm{Mg}_{0.2} \mathrm{Zn}_{0.8} \mathrm{O} / \mathrm{Pt}$ devices showed a reversible and stable resistance switching characteristic. The dominant conduction mechanisms of LRS and HRS were explained by Ohmic behavior and trap-controlled space charge limited current, respectively. Further study showed that increasing $\mathrm{Mg}$ contents in $\mathrm{MgZnO}$ thin films, the thin films formed a spinel-like structure, and a colossal resistance switching effect in the polycrystalline spinel-like structure $\mathrm{MgZnO}$ thin films with high $\mathrm{Mg}$ contents sandwiched by Pt electrodes was discovered. Figure 3 shows $I-V$ behavior of memory cell in semilog scale based on $\mathrm{Pt} /$ spinel- $\mathrm{Mg}_{0.8} \mathrm{Zn}_{0.2} \mathrm{O} / \mathrm{Pt}$ devices. The ultrahigh resistance ratio of high resistance state to low resistance state of about seven to nine orders of magnitude with a low reset voltage of less than $1 \mathrm{~V}$ was obtained in this thin film system. Obviously, this colossal resistance switching effect will greatly improve the

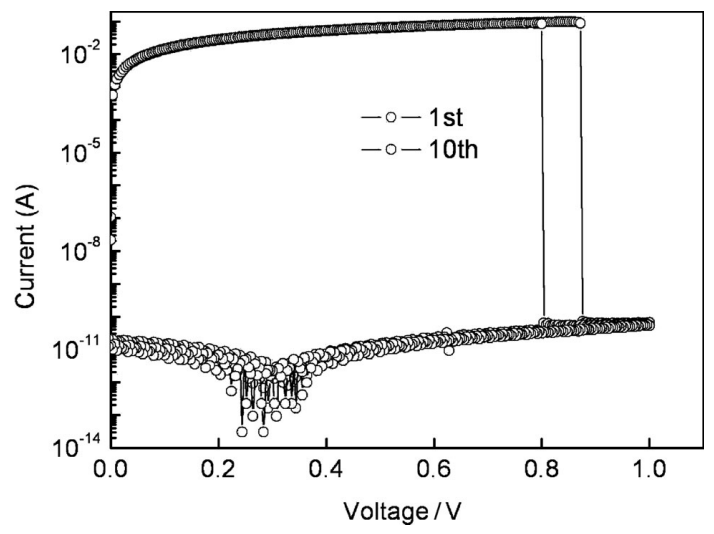

Fig. 3. $I-V$ behavior of memory cell in semilog scale based on $\mathrm{Pt} /$ spinel- $\mathrm{Mg}_{0.8} \mathrm{Zn}_{0.2} \mathrm{O} / \mathrm{Pt}$ devices. ${ }^{42}$ 
signal-to-noise ratio and simplify the process of reading memory state for nonvolatile memory applications. This study also provides a material base for studying the origin of resistance switching phenomenon.

Besides $\mathrm{Mg}$ doping in $\mathrm{ZnO}$ thin films, more recently, Mn doped $\mathrm{ZnO}$ thin films were prepared for RRAM application. ${ }^{43)} \mathrm{The} \mathrm{Ag} /$ $\mathrm{ZnO}: \mathrm{Mn} / \mathrm{Pt}$ structures exhibited excellent resistance properties such as ultrafast programming speed of $5 \mathrm{~ns}$, ultrahigh resistance ratio of $10^{7}$, long retention time of more than $10^{7} \mathrm{~s}$, good endurance, and high reliability at elevated temperatures. Furthermore, realization of visualization of nanoscale Ag bridges penetrating through the memory film could account for the high conductivity in low resistance state. Therefore, formation and rupture of the $\mathrm{Ag}$ bridges is suggested to explain the switching effect. These results indicated that $\mathrm{Ag} / \mathrm{ZnO}: \mathrm{Mn} / \mathrm{Pt}$ device represents an ultrafast and highly scalable (down to sub-100-nm range) resistive memory element for next generation nonvolatile memories.

$\mathrm{ZnO}$ thin films were also prepared on flexible plastic substrates by sol-gel method for flexible resistance switching memory applications. ${ }^{44)}$ Fast programming (less than $50 \mathrm{~ns}$ ) and a high resistance ratio (higher than $10^{4}$ ) was demonstrated. The devices fabricated on a flexible plastic substrates exhibited excellent durability after repetitive bending tests, demonstrating their potential for flexible low-cost memory devices.

In addition, highly transparent resistive random access memory device is of much interest for future see-through devices. Seo et al. fabricated ITO (indium tin oxide)/ZnO/ITO structure and studied its resistive switching characteristics. ${ }^{45)}$ The ITO/ZnO/ ITO structure including the substrate had a transmittance of $81 \%$ in the visible region and an excellent switching behavior under $3 \mathrm{~V}$. The retention study suggests that the ITO/ZnO/ITO device could maintain its memory property for more than 10 years.

\section{$2.4 \mathrm{Al}_{2} \mathrm{O}_{3}, \mathrm{CuO}, \mathrm{MnO}_{x}$, and $\mathrm{MgO}_{x}$ thin films}

Unipolar resistive switching of aluminum oxide thin films with $\mathrm{Al} / \mathrm{Al}_{x} \mathrm{O}_{y} / \mathrm{Al}$ structure was recently studied for flexible nonvolatile memory application. ${ }^{46)}$ The aluminum oxide $\left(\mathrm{Al}_{x} \mathrm{O}_{y}\right)$ thin films were prepared by plasma oxidation, and a high resistance ratio (higher than $10^{4}$ ) is achieved. Due to the good ductility of aluminum, the performance of resistive switching on a flexible substrate is not degraded by severe substrate bending. Note that the low process temperature of the plasma oxidation process is also advantageous for the fabrication of flexible electronic devices and modern interconnection processes.

Radio frequency sputtered aluminum oxide thin films also showed resistive switching behavior with a resistance ratio of high resistance state and low resistance state of over $10^{3}{ }^{47)}$ It is observed that both high resistance state and low resistance state are stable and reproducible during successive resistive switching by dc voltage sweeping.

Recent study showed that $\mathrm{CuO}_{x}$ thin film with gradual oxygen concentration distribution enhanced resistive switching characteristics for RRAM applications. ${ }^{48)}$ By using $\mathrm{Al} / \mathrm{CuO}_{x} / \mathrm{Cu}$ structure with gradual oxygen concentration, not only no forming is needed but also the endurance of switching is greatly enhanced.

$\mathrm{Pt} / \mathrm{MnO}_{x} / \mathrm{Al}$ structure was found to exhibit reversible resistive switching behavior. ${ }^{49)}$ When $\mathrm{Al}$ was used as the top electrode instead of $\mathrm{Pt}$, the device had a better endurance performance. Additionally, the $\mathrm{Pt} / \mathrm{MnO}_{x} / \mathrm{Al}$ device showed fast switching speed and long retention ability.

Nonvolatile and reversible resistance switching of copper doped $\mathrm{MoO}_{x}$ film was studied ${ }^{50)}$ Figure 4 shows endurance of $\mathrm{Cu}: \mathrm{MoO}_{x}$ by voltage pulses, and retention properties of $R_{\mathrm{on}}$ and
$R_{\text {off }}$ at RT and $85^{\circ} \mathrm{C}$. The resistance switching might be strongly related to the rupture and generation of multifilaments confirmed by spreading resistance images of a conducting atomic force microscope as well as filamentary conduction by double logarithmic plots. Based on the X-ray photoelectron spectroscopy analysis, it was thought that local conducting filaments could be formed by thermally diffused copper into $\mathrm{MoO}_{x}$ film from the bottom electrode.

In addition, $\mathrm{MgO}_{x}$ films deposited on silicon substrates using a reactive radio frequency magnetron sputtering clearly exhibited reproducible resistance switching behaviors with an improved stability. ${ }^{51)}$

\section{Several multilayered or metal nanocomposite transition metal oxide thin films}

Resistive switching characteristics of $\mathrm{Al}_{2} \mathrm{O}_{3} / \mathrm{TiO}_{2}$ and $\mathrm{Al}_{2} \mathrm{O}_{3}$ /

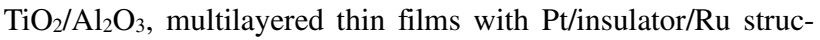
ture were studied. ${ }^{52)}$ For comparison, $\mathrm{TiO}_{2}$ and $\mathrm{Al}_{2} \mathrm{O}_{3}$ thin films were prepared with the same $\mathrm{Pt} / \mathrm{insulator} / \mathrm{Ru}$ structure. Both $\mathrm{TiO}_{2}$ films and $\mathrm{Al}_{2} \mathrm{O}_{3}$ films show resistive switching by a filamentary switching mechanism with linear conduction behavior in the low $\mathrm{V}$ region. The multilayered thin films showed a bias polaritydependent switching behavior. This suggested that the nucleation of the conducting filaments could occur at the interface where the electrons were injected.

Both lowering the "reset" current and raising the resistance in the low resistance state are crucial for practical use of RRAM. Kinoshita et al. prepared a heterojunction structure consisting of transition metal oxides, $\mathrm{NiO}_{y} / \mathrm{TiO}_{x} / \mathrm{Pt}$, combining direct contact with the $\mathrm{NiO}_{y}$ using a W-probe ${ }^{53)}$ Figure 5 shows $I-V$ curve during the reset process for W-probe/NiOy/TiOx/Pt (closed circles) together with $\mathrm{Pt} / \mathrm{NiOy} / \mathrm{Pt}$ (closed triangles). As a result, this structure could lead to extreme downsizing of the effective area of both the top and bottom electrodes for $\mathrm{NiO}_{y}$ and thus
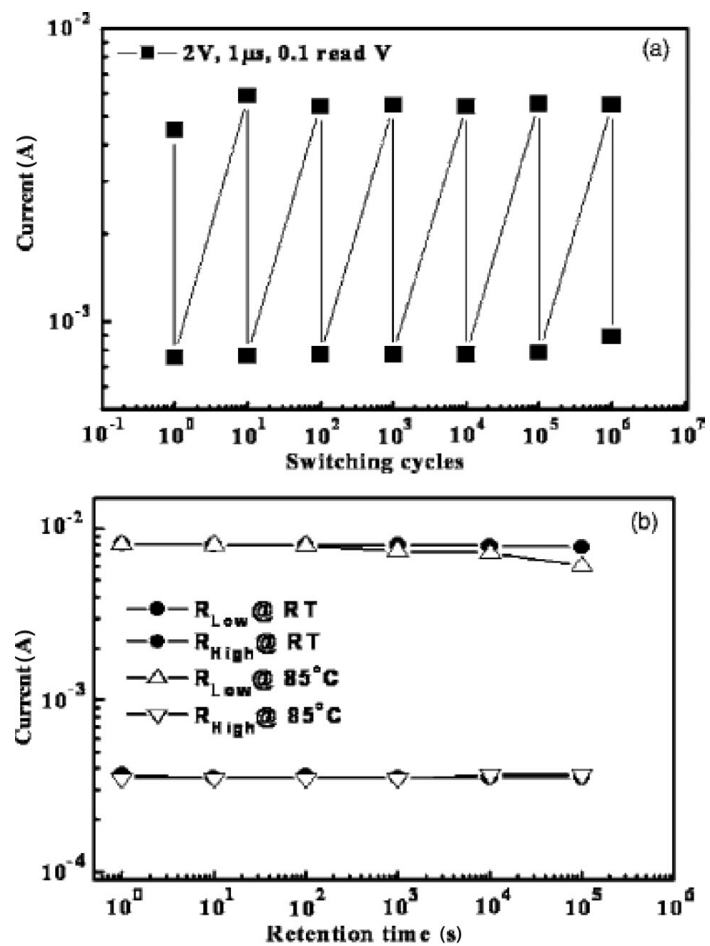

Fig. 4. Endurance of $\mathrm{Cu}: \mathrm{MoO}_{x}$ by voltage pulses, and retention properties of $R_{\text {on }}$ and $R_{\text {off }}$ at $\mathrm{RT}$ and $85^{\circ} \mathrm{C}^{50)}$ 


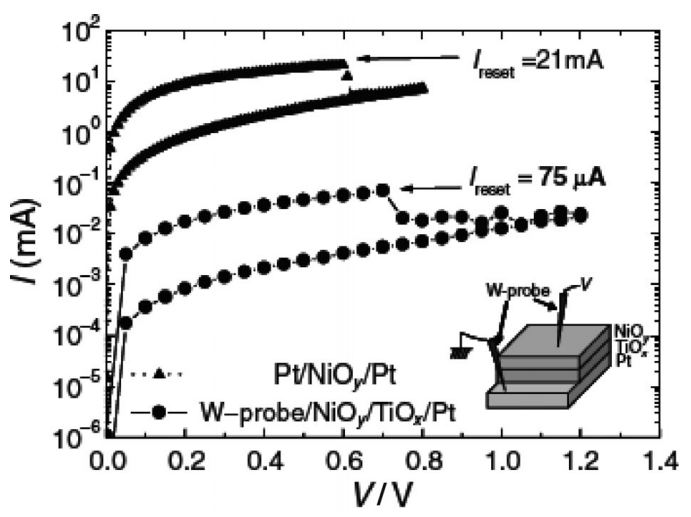

Fig. 5. $I-V$ curve during the reset process for $\mathrm{W}$-probe/ $/ \mathrm{NiO}_{y} / \mathrm{TiO}_{x} / \mathrm{Pt}$ (closed circles) together with $\mathrm{Pt} / \mathrm{NiO}_{y} / \mathrm{Pt}$ (closed triangles). Measurement configuration for the $I-V$ measurement on $\mathrm{W}$-probe/ $/ \mathrm{NiO}_{y} / \mathrm{TiO}_{x} / \mathrm{Pt}$ is shown in the inset. ${ }^{53)}$

decreased the number of filaments formed in "forming" process. Reducing the number of filaments is essential to the issues of lowering the "reset" current and raising the resistance.

Considering that both $\mathrm{NiO}$ and $\mathrm{MgZnO}$ on Pt electrodes exhibit resistive switching effect, Bao et al. proposed a heterojunction structure composed of $\mathrm{p}-\mathrm{NiO}$ and $\mathrm{n}-\mathrm{MgZnO}$ with high $\mathrm{Mg}$ contents with an aim to tuning or improving the resistive switching properties. ${ }^{54)}$ The $\mathrm{p}-\mathrm{NiO} / \mathrm{n}-\mathrm{MgZnO}$ heterojunction was fabricated on $\mathrm{Pt} / \mathrm{TiO}_{2} / \mathrm{SiO}_{2} / \mathrm{Si}$ substrates by sol-gel spin coating technique. It has been confirmed that the $\mathrm{p}-\mathrm{n}$ heterojunction device exhibited typical current-voltage $(I-V)$ behaviors with rectifying characteristics. After an electroforming process, the $\mathrm{Pt} / \mathrm{NiO} / \mathrm{MgZnO} / \mathrm{Pt}$ heterojunction device showed good reproducible resistance switching properties, such as a reduced threshold current of $1 \mu \mathrm{A}$ for device initiation, a small dispersion of reset voltage ranging from 0.55 to $0.62 \mathrm{~V}$, and a high resistance ratio of high resistance state to low resistance state about six orders of magnitude.

Bilayered thin films combining eicosanoic acid (EA) and $\mathrm{ZrO}_{2}$ with a sandwich structure of $\mathrm{Al} / \mathrm{EA} / \mathrm{ZrO}_{2} / \mathrm{Au}$ also showed resistance switching characteristics. ${ }^{55)}$ The $\mathrm{Al} / \mathrm{EA} / \mathrm{ZrO}_{2} / \mathrm{Au}$ devices exhibited asymmetric electrical bistable behavior with a rectifying effect. The asymmetry and rectifying bistable behavior was thought to result from the Schottky barrier due to the $\mathrm{ZrO}_{2}$ layer/ $\mathrm{Au}$ interface. Reversible and reproducible bistable switching properties were observed.

Besides multilayered structure thin films for RRAM application, metal $\mathrm{Au}$ or $\mathrm{Ag}$ or $\mathrm{Cu}$ nanocomposite transition metal oxide thin films were prepared for the same aims.

Guan et al. studied resistive switching characteristics of $\mathrm{Au}-$ $\mathrm{ZrO}_{2}$ thin films with top electrode/ $\mathrm{Au}-\mathrm{ZrO}_{2} / \mathrm{n}^{+} \mathrm{Si}$ sandwich structure ${ }^{56)}$ Figure 6 shows typical $I-V$ characteristics of Au$\mathrm{ZrO}_{2}$ in semilog scale. The voltage is swept in the direction as follows: $0 \mathrm{~V} \rightarrow 4 \mathrm{~V} \rightarrow 0 \mathrm{~V} \rightarrow 4 \mathrm{~V} \rightarrow 0 \mathrm{~V}$. By applying proper voltage, reproducible resistive switching between high resistance state and low resistance state can be achieved with a resistance ratio of high resistance state and low resistance state about two orders. In comparison, $\mathrm{Cu} / \mathrm{ZrO}_{2}: \mathrm{Cu} / \mathrm{Pt}$ sandwiched structure also showed resistive switching behavior with a resistance ratio of the order of $10^{6}{ }^{57)}$ The switching mechanism is believed to be related to the formation and rupture of conducting filamentary paths. In addition, $\mathrm{Au} / \mathrm{Cr} / \mathrm{Zr}^{+}$-implanted $-\mathrm{ZrO}_{2} / \mathrm{n}^{+}-\mathrm{Si}$ sandwiched structure exhibited reversible bipolar resistive switching behavior under dc sweeping voltage with a resistance ratio as high as five orders of magnitude at $0.5 \mathrm{~V}$ readout bias. ${ }^{58)}$

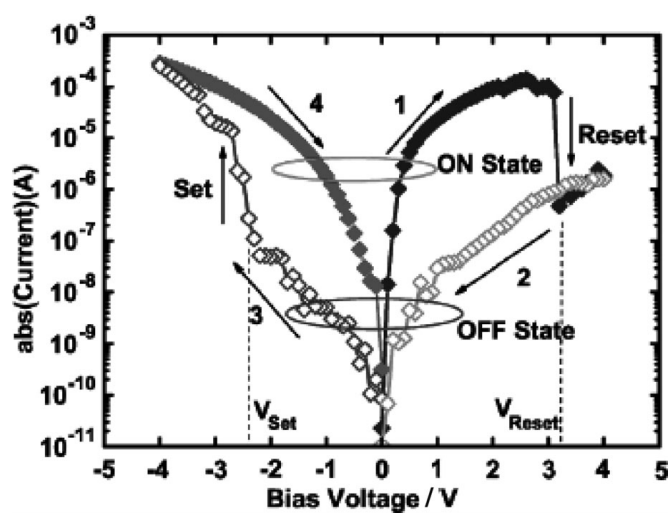

Fig. 6. Typical $I-V$ characteristics of sample $\mathrm{Au}-\mathrm{ZrO}_{2}$ in semilog scale. The voltage is swept in the direction as follows: $0 \mathrm{~V} \rightarrow 4 \mathrm{~V} \rightarrow 0 \mathrm{~V}$ $\rightarrow 4 \mathrm{~V} \rightarrow 0 \mathrm{~V}^{56)}$

Sol-gel derived Ag-doped $\mathrm{ZrO}_{2}$ thin films on $\mathrm{Pt} / \mathrm{Ti} / \mathrm{SiO}_{2} / \mathrm{Si}$ substrates were reported to show improved resistive switching characteristics. ${ }^{59)}$ The improved resistive switching behavior in the Ag doped $\mathrm{ZrO}_{2}$ thin films could be attributed to Ag doping effect on the formation of the stable filamentary conducting paths.

Although $\mathrm{SiO}_{2}$ is not a transition metal oxide, $\mathrm{Cu}$-doped $\mathrm{SiO}_{2}$ thin films with $\mathrm{W} / \mathrm{Cu}-\mathrm{SiO}_{2} / \mathrm{Cu}$ structure were reported to show resistive switching properties. ${ }^{60)-61)}$ Such devices based on resistance switching in copper-doped silicon oxide are of particular interest because they are compatible with back-end-of-line processing for CMOS integrated circuits.

Recently, Verbakel et al. made an attempt to fabricate diodes based on spin-coated layers of nanoparticles of $\mathrm{Al}_{2} \mathrm{O}_{3}, \mathrm{CeO}_{2}$, $\mathrm{TiO}_{2}, \mathrm{ZrO}_{2}, \mathrm{Y}_{2} \mathrm{O}_{3}$, or $\mathrm{ZnO}$ and a semiconducting polymer sandwiched between two electrodes. ${ }^{62)}$ It was found that inclusion of the metal oxide nanoparticles results in similar nonvolatile resistance switching properties to those observed for the corresponding "bulk" oxides. Furthermore, the nano-particle-containing polymer layers do not require an electroforming process. This research is also of interest for flexible RRAM applications.

\section{Conclusions}

Binary transition metal oxide thin films having reversible bistable resistance switching behaviors exhibit good potential for nonvolatile resistive random access memory applications. By doping suitable compositions in transition metal oxide thin films, or constructing multilayered structure thin films, or preparing metal nanocomposite thin films, the resistance switching behaviors can be enhanced or improved. More efforts should be made to better understand the switching mechanisms including effects of interface between electrode and oxide film and defects such as oxygen vacancies, grain boundaries. There is no doubt that study on transition metal oxide thin films for RRAM application will have been a topic of great interest in the forthcoming years, and it is expected that better understanding of physical mechanisms for the bistable resistance switching of the transition metal oxide thin films sandwiched between two metal electrodes will speed up the resistive random access memory applications of the transition metal oxide thin films.

Acknowledgments The author gratefully acknowledges support from NSFC (No. 50872156, No. 10574164, and No. U0634006), the Natural Science Foundation of Guangdong Province, China (No. 05003289), and the Specialized Research Fund for the Doctoral Program of Higher Education of China (No. 20060558068). 


\section{References}

1) D. B. Strukov, G. S. Snider, D. R. Stewart and R. S. Williams, Nature, 453, 80 (2008).

2) M. J. Lee, S. Seo, D. C. Kim, S. E. Ahn, D. H. Seo, I. G. Baek, D. S. Kim, I. S. Byun, S. H. Kim, I. R. Huang, J. S. Kim, S. H. Jeon and B. H. Park, Adv. Mater., 19, 73 (2007).

3) R. Waser and M. Aono, Nat. Mater., 6, 833-840 (2007).

4) Y. B. Nian, J. Strozier, N. J. Wu et al., Phys. Rev. Lett., 98, $146403(2007)$

5) J. J. Yang, M. D. Pickett, X. Li, D. A. A. Ohlberg, D. R. Stewart and R. S. Williams, Nature Nanotechnology, 3, 429-433 (2008).

6) S. H. Chang, J. S. Lee, S. C. Chae et al., Phys. Rev. Lett., 102, 026801 (2009).

7) A. Sawa, Mater. Today, 11, 28 (2008).

8) A. Ignatiev, N. J. Wu, X. Chen, S. Q. Liu, C. Papagianni and J. Strozier, Phys. Stat. Sol. B, 243, 2089-2097 (2006).

9) A. Ignatiev, N. J. Wu, X. Chen, Y. B. Nian, C. Papagianni, S Q. Liu and J. Strozier, Phase Transit., 81, 791-806 (2008).

10) C. Y. Lin, C. Y. Liu, C. C. Lin and T. Y. Tseng, J. Electroceram., 21, 61-66 Sp. Iss. SI (2008).

11) G. S. Park, X. S. Li, D. C. Kim, R. J. Jung, M. J. Lee and S. Seo, Appl. Phys. Lett., 91, 222103 (2007).

12) J. B. Yun, S. Kim, S. Seo, M. J. Lee, D. C. Kim, S. E. Ahn, Y. Park, J. Kim and H. Shin, Phys. Stat. Sol.-Rapid Res. Lett., 1, 280-282 (2007).

13) J. Y. Son and Y. H. Shin, Appl. Phys. Lett., 92, 222106 (2008).

14) U. Russo, D. Ielmini, C. Cagli and A. L. Lacaita, IEEE Trans. Electron Devices, 56, 186-192 (2009).

15) K. Jung, H. Seo, Y. Kim, H. Im, J. Hong, J. W. Park and J. K. Lee, Appl. Phys. Lett., 90, 052104 (2007).

16) J. W. Park, J. W. Park, K. Jung, M. K. Yang and J. K. Lee, J. Vac. Sci. Technol. B, 24, 2205-2208 (2006).

17) C. Park, S. H. Jeon, S. C. Chae, S. Han, B. H. Park, S. Seo and D. W. Kim, Appl. Phys. Lett., 93, 042102 (2008).

18) C. B. Lee, B. S. Kang, M. J. Lee, S. E. Ahn, G. Stefanovich, W. X. Xianyu, K. H. Kim, J. H. Hur, H. X. Yin, Y. Park, I. K. Yoo, J. B. Park and B. H. Park, Appl. Phys. Lett., 91, 082104 (2007).

19) C. B. Lee, B. S. Kang, A. Benayad, M. J. Lee, S. E. Ahn, K. H. Kim, G. Stefanovich, Y. Park and I. K. Yoo, Appl. Phys. Lett., 93, 042115 (2008).

20) S. H. Phark, R. Jung, Y. J. Chang, T. W. Noh and D. W. Kim, Appl. Phys. Lett., 94, 022906 (2009).

21) K. Jung, J. Choi, Y. Kim, H. Im, S. Seo, R. Jung, D. Kim, J. S. Kim, B. H. Park and J. P. Hong, J. Appl. Phys., 103, 034504 (2008).

22) D. C. Kim, M. J. Lee, S. E. Ahn, S. Seo, J. C. Park, I. K. Yoo, I. G. Baek, H. J. Kim, E. K. Yim, J. E. Lee, S. O. Park, H. S. Kim, U. I. Chung, J. T. Moon and B. I. Ryu, Appl. Phys. Lett., 88, 232106 (2006).

23) Y. Sato, K. Tsunoda, K. Kinoshita, H. Noshiro, M. Aoki and Y. Sugiyama, IEEE Trans. Electron Devices, 55, 1185-1191 (2008).

24) C. Yoshida, K. Tsunoda, H. Noshiro and Y. Sugiyama, Appl. Phys. Lett., 91, 223510 (2007)

25) M. Fujimoto, H. Koyama, M. Konagai, Y. Hosoi, K. Ishihara, S. Ohnishi and N. Awaya, Appl. Phys. Lett., 89, 223509 (2006).

26) W. Y. Chang, Y. T. Ho, T. C. Hsu, F. Chen, M. J. Tsai and T. B. Wu, Electrochem. Solid-Stat. Lett., 12, H135-H137 (2009).

27) K. M. Kim, B. J. Choi, D. S. Jeong, C. S. Hwang and S. Han, Appl. Phys. Lett., 89, 162912 (2006).

28) K. M. Kim, B. J. Choi and C. S. Hwang, Appl. Phys. Lett., 90, 242906 (2007)

29) J. S. Kwak, Y. H. Do, J. H. Lee, J. P. Hong, B. H. Park, H. S. Im and S. J. Woo, J. Korean Phys. Soc., Part 1 Sp. Iss. SI. 53, 3685-3689 (2008)

30) L. F. Liu, J. F. Kang, N. Xu, X. Sun, C. Chen, B. Sun, Y. Wang, X. Y. Liu, X. Zhang and R. Q. Han, Jpn. J. Appl. Phys., 47, 2701-2703 Part 2 (2008).
31) S. Won, S. Go, K. Lee and J. Lee, Electron. Mater. Lett., 4, 29-33 (2008).

32) D. Lee, H. Choi, H. Sim, D. Choi, H. Hwang, M. J. Lee, S. A. Seo and I. K. Yoo, IEEE Electron Dev. Lett., 26, 719-721 (2005).

33) C. Y. Lin, C. Y. Wu, C. Y. Wu, T. C. Lee, F. L. Yang, C. Hu and T. Y. Tseng, IEEE Electron Dev. Lett., 28, 366-368 (2007).

34) S. Lee, W. G. Kim, S. W. Rhee and K. Yong, J. Electrochem. Soc., 155, H92-H96 (2008).

35) H. Y. Lee, P. S. Chen, C. C. Wang, S. Maikap, P. J. Tzeng, C. H. Lin, L. S. Lee and M. J. Tsai, Jpn. J. Appl. Phys., PART 1, 46, 2175-2179 (2007).

36) C. Y. Lin, D. Y. Lee, S. Y. Wang, C. C. Lin and T. Y. Tseng, Surf. \& Coat Technol., 203, 480-483 (2008).

37) M. Villafuerte, S. P. Heluani, G. Juarez, G. Simonelli, G. Braunstein and S. Duhalde, Appl. Phys. Lett., 90, 052105 (2007).

38) W. Y. Chang, Y. C. Lai, T. B. Wu, S. F. Wang, F. Chen and M. J. Tsai, Appl. Phys. Lett., 92, 022110 (2008).

39) N. Xu, L. F. Liu, X. Sun, C. Chen, Y. Wang, D. D. Han, X. Y. Liu, R. Q. Han, J. F. Kang and B. Yu, Semicond. Sci. Technol., 23, 075019 (2008).

40) N. Xu, L. F. Liu, X. Sun, X. Y. Liu, D. D. Han, Y. Wang, R. Q. Han, J. F. Kang and B. Yu, Appl. Phys. Lett., 92, 232112 (2008).

41) X. M. Chen, G. H. Wu and D. H. Bao, Appl. Phys. Lett., 93, 093501 (2008).

42) X. M. Chen, G. H. Wu, P. Jiang, W. F. Liu and D. H. Bao, Appl. Phys. Lett., 94, 033501 (2009).

43) Y. C. Yang, F. Pan, Q. Liu, M. Liu and F. Zeng, Nano Lett., 9, 1636-1643 (2009).

44) S. Kim, H. Moon, D. Gupta, S. Yoo and Y. K. Choi, IEEE Trans. Electron Devices, 56, 696-699 (2009).

45) J. W. Seo, J. W. Park, K. S. Lim, J. H. Yang and S. J. Kang, Appl. Phys. Lett., 93, 223505 (2008).

46) S. Kim and Y. K. Choi, Appl. Phys. Lett., 92, 223508 (2008).

47) C. Y. Lin, C. Y. Wu, C. Y. Wu, C. Hu and TY Tseng, J. Electrochem. Soc., 154, G189-G192 (2007).

48) P. Zhou, H. B. Lv, M. Yin, L. Tang, Y. L. Song, T. A. Tang, Y. Y. Lin, A. Bao, A. Wu, S. Cai, H. Wu, C. Liang and M. H. Chi, J. Vac. Sci. Technol. B, 26, 1030-1032 (2008).

49) S. Zhang, S. B. Long, W. H. Guan, Q. Liu, Q. Wang and M. Liu, J. Phys. D: Appl. Phys., 42, 055112 (2009).

50) D. Lee, D. J. Seong, I. Jo, F. Xiang, R. Dong, S. Oh and H. Hwang, Appl. Phys. Lett., 90, 122104 (2007).

51) K. W. Jeong, Y. H. Do, K. S. Yoon, C. O. Kim and J. P. Hong, J. Korean Phys. Soc., 48, 1501-1504 (2006).

52) K. M. Kim, B. J. Choi, B. W. Koo, S. Choi, D. S. Jeong and C. S. Hwang, Electrochem. Solid-State Lett., 9, G343-G346 (2006).

53) K. Kinoshita, T. Tamura, M Aoki, Y. Sugiyama and H. Tanaka, Jpn. J. Appl. Phys., 45, L991 (2006).

54) X. M. Chen and D. H. Bao, to be published.

55) D. Tu, M. Liu, L. W. Shang, X. H. Liu and C. Q. Xie, Appl. Phys. Lett., 92, 123302 (2008).

56) W. H. Guan, S. B. Long, R. Jia and M. Liu, Appl. Phys. Lett., 91, 062111 (2007)

57) W. H. Guan, S. B. Long, Q. Liu, M. Liu, W. Wang, IEEE Electron Dev. Lett., 29, 434-437 (2008).

58) Q. Liu, W. H. Guan, S. B. Long, R. Jia, M. Liu and J. N. Chen, Appl. Phys. Lett., 92, 012117 (2008).

59) B. Sun, L. F. Liu, D. D. Han, Y. Wang, X. Y. Liu, R. Q. Han and J. F. Kang, Chin. Phys. Lett., 25, 2187-2189 (2008).

60) C. Schindler, S. C. P. Thermadam, R. Waser and M. N. Kozicki, IEEE Trans Electron Devices, 54, 2762-2768 (2007).

61) C. Schindler, G. Staikov, R. Waser, Appl. Phys. Lett., 94, 072109 (2009).

62) F. Verbakel, S. C. J. Meskers, D. M. de Leeuw and R. A. J. Janssen, J. Phys. Chem. C, 112, 5254-5257 (2008). 